\title{
Ceftaroline in the management of complicated skin and soft tissue infections and community acquired pneumonia
}

This article was published in the following Dove Press journal:

Therapeutics and Clinical Risk Management

7 April 2015

Number of times this article has been viewed

\author{
Mbiye A Mpenge' \\ Alasdair P MacGowan² \\ 'Department of Medical Microbiology, \\ University Hospitals Bristol NHS \\ Trust, Bristol Royal Infirmary, Bristol, \\ England; ${ }^{2}$ Department of Medical \\ Microbiology, North Bristol NHS \\ Trust, Southmead Hospital, Bristol, \\ England
}

\begin{abstract}
Ceftaroline is a new parenteral cephalosporin approved by the European Medicines Agency (EMA) and the US Food and Drug Administration (FDA) for the treatment of complicated skin and soft tissue infections (cSSTIs) including those due to methicillin-resistant Staphylococcus aureus (MRSA), and community-acquired pneumonia (CAP). Ceftaroline has broad-spectrum activity against gram-positive and gram-negative bacteria and exerts its bactericidal effects by binding to penicillin-binding proteins (PBPs), resulting in inhibition of bacterial cell wall synthesis. It binds to PBP 2a of MRSA with high affinity and also binds to all six PBPs in Streptococcus pneumoniae. In in vitro studies, ceftaroline demonstrated potent activity against Staphylococcus aureus (including MRSA and vancomycin-intermediate isolates), Streptococcus pneumoniae (including multidrug resistant isolates), Haemophilus influenzae, Moraxella catarrhalis, and many common gram-negative pathogens, excluding extended spectrum betalactamase (ESBL)-producing Enterobacteriaceae and Pseudomonas aeruginosa. In Phase II and Phase III clinical trials, ceftaroline was noninferior to its comparator agents and demonstrated high clinical cure rates in the treatment of cSSTIs and CAP. It demonstrated favorable outcomes in patients treated for both regulatory-approved indications and unlicensed indications in a retrospective analysis. Ceftaroline is a safe and effective option for treatment in specific patient populations in which its efficacy and safety have been proven. This article reviews the challenges in the treatment of cSSTI and CAP, ceftaroline and its microbiology, pharmacology, efficacy, and safety data which support its use in treatment of cSSTIs and CAP.
\end{abstract}

Keywords: ceftaroline, cephalosporin, cSSTI, CAP, Staphylococcus aureus, Streptococcus pneumoniae

\section{Introduction}

The emergence and rising prevalence of antimicrobial resistant strains of common pathogens has led to challenges in the management of serious infections, including complicated skin and soft tissue infections (cSSTIs) and community-acquired pneumonia (CAP). The reducing efficacy of antimicrobial agents against resistant organisms and the toxicity of various antibiotics are a cause for concern. New antimicrobial agents against which common organisms have reduced potential for resistance, with reduced toxicity and wide-spectrum bactericidal activity, including activity against methicillin-resistant Staphylococcus aureus (MRSA) and common multidrug resistant organisms, are required for the treatment of complex bacterial infections.

\section{Complicated skin and soft tissue infections}

Skin and soft tissue infections (SSTIs) have diverse causes which depend partly on the epidemiological setting and may be determined through history taking, physical 
examination, and diagnostic procedures. ${ }^{1}$ SSTIs may be classified according to the anatomical site of infection, microbial etiology, or severity. ${ }^{2}$

Complicated skin and soft tissue infections are the more severe end of the spectrum of all SSTIs or Class 2 onwards in the Eron classification (either systemically unwell or systemically well but with comorbidity; toxic and unwell; and/or sepsis syndrome and life-threatening infection). ${ }^{2}$ cSSTIs can therefore range from severe infection in healthy individuals to mild/moderate infection in patients with significant comorbidities; extensive cellulitis requiring antibiotic treatment alone to necrotizing infection requiring surgery. ${ }^{2}$ They usually manifest with fever, hypothermia, tachycardia, and hypotension. ${ }^{1,3}$

SSTIs are usually caused by Staphylococcus aureus (S. aureus) $)^{4}$ and beta-hemolytic Streptococci, groups A, B, C, and G. Group B Streptococcus is common in elderly and diabetic patients. ${ }^{1,5}$ Surgical site infections are commonly caused by gram-negative and anaerobic bacteria while multiple organisms infect ischemic tissue. ${ }^{2}$

Methicillin-resistance was initially detected in $S$. aureus in $1961,{ }^{6}$ and has caused a worldwide epidemic over the last few decades. ${ }^{7,8}$ MRSA rates have varied between countries and continents, with the highest rates in North America (35.9\%), followed by Latin America (29.4\%), and Europe (22.8\%). ${ }^{9}$ Infection with true community-acquired MRSA (CA-MRSA) has also increased in parts of North America and Europe. ${ }^{10,11}$

Asia was among the regions with the highest prevalence of health care-associated (HA) and CA-MRSA in the world. Most of the hospitals in Asia were endemic for multidrugresistant MRSA, with a ratio estimated from 28\% (in Hong Kong and Indonesia) to $>70 \%$ (in Korea) among all clinical S. aureus isolates in early 2010. The rate of MRSA among $\mathrm{CA}-\mathrm{S}$. aureus infection in Asian countries varied from $<5 \%$ to $>35 \%$. $^{12}$

In a Californian clinic, $S$. aureus was isolated from $83 \%$ of 837 positive cultures from SSTIs and $76 \%$ of these isolates were MRSA. ${ }^{13}$ A study of 422 patients presenting at emergency rooms across the USA with SSTIs showed that $59 \%$ of the cases were due to CA-MRSA. ${ }^{14}$

In a three-year US population-based study, 471,550 SSTI episodes were reported in 376,262 individuals. Eighty-one percent of culture-positive episodes were due to $S$. aureus, of which $46 \%$ were MRSA. ${ }^{15}$

During the 2012 European Antimicrobial Resistance Surveillance (EARS), a majority of the countries reported MRSA proportions of $<20 \%$. The EU/EEA population-weighted average was $17.8 \%$ and has declined over the preceding 4 years.
Seven countries (Cyprus, Greece, Italy, Malta, Poland, Portugal, and Romania) reported MRSA proportion of $>25 \%$. ${ }^{16}$

A Europe-wide survey of experience with MRSA reported SSTIs (79\%) as the common infections. The most common underlying foci in patients with MRSA bacteremia were intravenous (IV) lines (48\%) and SSTIs. ${ }^{17}$ Another study of SSTIs in European medical centers showed S. aureus as the most common pathogen (71\% of cases), with $22.5 \%$ of the isolates being MRSA. ${ }^{18}$ MRSA proportion varied among countries and ranged from $0.4 \%$ in Sweden to $48.4 \%$ in Belgium. ${ }^{19}$

The surveillance of surgical site infections in England over a period of 5 years reported at least one causative pathogen for $77 \%$ of surgical site infections. S. aureus was the most common pathogen and it accounted for $38 \%$ of surgical site infections, of which $64 \%$ were MRSA. ${ }^{20}$ However, the proportion of MRSA isolates, which accounted for $31 \%$ of surgical site infections reduced to $32 \%$ between October 2008 and September $2009 .{ }^{21}$ The reduction in rates of MRSA bacteremia may be reflected by this decline.

\section{Challenges in the treatment of cSSTIs}

SSTIs, especially those due to $S$. aureus, can result in bacteremia, which is sometimes associated with metastatic foci of infection. ${ }^{22}$

Antibiotics with or without surgical debridement are the mainstay of management of cSSTIs. The emergence of strains with resistance to multiple antimicrobials has led to challenges in choosing empirical antibiotic treatment. Suspected streptococcal and methicillin-sensitive S. aureus (MSSA) infections are mainly treated with beta-lactam antibiotics. ${ }^{23}$ Empirical antibiotic treatment is determined by knowledge of the most likely infecting microorganism, local susceptibility patterns, and patient characteristics like age, kidney and liver function, hypersensitivity to antibiotics, and previous antibiotic treatment. ${ }^{24}$

According to UK MRSA guidelines, if the local MRSA prevalence is $>10 \%$ of $S$. aureus isolates, then the empirical antibiotic therapy of a suspected $S$. aureus infection should include an agent with activity against MRSA. ${ }^{25}$

Parenteral antibiotics licensed for the treatment of cSSTIs with activity against MRSA include vancomycin, quinupristin/dalfopristin, linezolid, daptomycin, telavancin, tigecycline, ceftaroline, ${ }^{26}$ and teicoplanin.

Vancomycin has been the main treatment option in MRSA infections and in patients with hypersensitivity to beta-lactams. However, vancomycin therapy in MSSA infection is associated with slower bacterial clearance 
and poorer clinical response in comparison to beta-lactam therapy. ${ }^{27}$ Reports of intermediate vancomycin resistance by various mechanisms have been rising and there are concerns over potential vancomcyin toxicity. ${ }^{23}$

Teicoplanin is usually preferred in patients who are intolerant to vancomcyin and is currently available in a number of European, Asian, and South American countries. ${ }^{28}$ Its plasma half-life $\left(t^{1} / 2\right)$ is long, enabling once-a-day dosing, ${ }^{29}$ and is therefore an option in patients requiring outpatient parenteral antibiotic therapy. S. aureus susceptible to vancomcyin but displaying high teicoplanin MICs was reported before the description of vancomycin intermediate sensitive Staphylococcus aureus (VISA) isolates. ${ }^{28}$ In March 2000, MRSA isolates that were intermediately resistant to teicoplanin were reported in Southampton and Portsmouth. Over a 1-year period (February 2000-February 2001), 75 isolates of MRSA from patients at Southampton General Hospital were not susceptible to teicoplanin and were found to belong to the UK epidemic strain, EMRSA-17 by phage typing and pulsed-field gel electrophoresis..$^{30}$ Resistance to linezolid, daptomycin, tigecycline, and telavancin has also emerged.

\section{CAP}

CAP is a lung infection that is not acquired in a hospital or a health care institution, and it causes significant morbidity and mortality. ${ }^{31}$

Pneumonia combined with influenza is the eighth leading cause of mortality in the US and the most common cause of infection-related death. ${ }^{32} \mathrm{CAP}$ has an overall annual incidence of 5-11 per 1,000 persons, with a higher number of cases occurring in winter. ${ }^{33}$ Streptococcus pneumoniae ( $S$. pneumoniae) was the most commonly identified organism in 4.2 million ambulatory care visits due to CAP in 2006. ${ }^{34}$

A UK population-based study showed a lower respiratory tract infection incidence increase, which was higher in men than women and rose with age from 92.21 episodes/1,000 person-years (in those aged 65-69) to 187.91/1,000 (in those aged 85-89). The incidence of CAP rose markedly with age, from 2.81 to 21.81 episodes/1,000 person-years respectively, and was also higher in men. ${ }^{35}$

A Finnish study demonstrated the dramatic rise in the incidence of CAP with age, with a sixfold incidence rise between ages $30-44$ and $\geq 75$ years. ${ }^{36}$ Case fatality rates in Portugal were $4.5 \%$ for $18-50$-year-old patients, $19.4 \%$ for those aged $\geq 50$ years, and $24.8 \%$ for patients $\geq 75$ years of age. ${ }^{37}$ Another UK study reported casefatality rates in patients aged $<65$ years of $5.6 \%$ and $47.2 \%$ in those $\geq 85$ years. A 12 -fold higher odds ratio for mortality was observed within 30 days of hospital admission for patients aged $\geq 85$ years than for those aged $<65$ years. ${ }^{38}$

CAP is predominantly caused by S. pneumoniae, a pathogen that is increasingly becoming resistant to various antimicrobial agents. Haemophilus influenzae (H. influenzae) is also frequent in outpatients, particularly smokers. ${ }^{39}$ Mycoplasma pneumoniae, Chlamydophila pneumoniae, Legionella species and respiratory viruses are common atypical respiratory pathogens. ${ }^{39}$ Enterobacteriacae are a rare cause of CAP in outpatients. Patients with underlying cardiopulmonary disease and other risk factors are vulnerable to infection with drug resistant $S$. pneumoniae, enteric gram-negative bacteria and Pseudomonas aeruginosa (P. aeruginosa) ${ }^{40}$ Severe CAP can also be caused by $S$. aureus, particularly after infection with influenza virus. Cases of CAP due to MRSA have appeared, but the occurrence is sporadic. ${ }^{41}$

\section{Challenges in the treatment of CAP}

The mortality rate of CAP 1 year post hospital discharge is high, especially in the elderly and those with comorbidities. ${ }^{42}$ A study showed that $25 \%$ of patients with CAP died in the following year after hospital discharge. A larger study reported a significantly higher mortality rate of $33 \%$ at 1 year in discharged elderly patients than that of hospitalized controls. ${ }^{42}$

The prevalence of drug-resistant strains of S. pneumoniae is rising. Resistance rates to penicillin rose from $<5 \%$ in 1987 to $11.8 \%$ during the 2001-2002 respiratory disease season. Sixteen percent of the isolates were intermediate penicillin resistant. ${ }^{43,44}$ Resistance rate to macrolides rose from $0.3 \%$ to $27.5 \%{ }^{45}$

In the 2012 EARS, S. pneumoniae showed large variations in antimicrobial susceptibility between European countries. A majority of the reporting countries had proportions of penicillin nonsusceptibility $<10 \%$, but four countries (Bulgaria, Malta, Romania, and Spain) reported proportions $>25 \%$. Macrolide nonsusceptibility was higher than proportions for penicillin nonsusceptibility. Dual nonsusceptibility to penicillin and macrolides was $<10 \%$ in more than half of the reporting countries. ${ }^{19}$

The proportion of S. pneumoniae isolates resistant to erythromycin, penicillin, levofloxacin, and telithromycin were reported as $29.3 \%, 21.2 \%, 0.9 \%$, and $0.02 \%$, respectively by a 2000-2004 longitudinal surveillance study in the USA. ${ }^{46}$

In 2003-2004, the Global Landscape on the Bactericidal Activity of Levofloxacin (GLOBAL) surveillance program 
tested the susceptibility of common respiratory microorganisms to commonly used antibiotics and demonstrated S. pneumoniae susceptibility to oral penicillin which ranged from $41.5 \%$ (in Asia) to $75.3 \%$ (in Europe). Erythromycin susceptibility ranged from $23.7 \%$ (in Asia) to $87.0 \%$ (in Central and South America). Levofloxacin susceptibility was $\geq 98.0 \%$ for each region studied, with the minimum inhibitory concentration $(90 \%)\left(\mathrm{MIC}_{90}\right)$ of $1 \mu \mathrm{g} / \mathrm{mL}$. H. influenzae resistance to ampicillin ranged from $8.7 \%$ (in South Africa) to $29.6 \%$ (in Asia), while resistance to trimethoprimsulfamethoxazole ranged from $15.3 \%$ (in the United States) to $40.3 \%$ (in Asia). ${ }^{47}$

In a study to determine the decreased susceptibility of S. pneumoniae to oral antimicrobial agents in Vietnamese children, 258 out of the 818 children (32\%) had respiratory infections, 421 (52\%) had S. pneumoniae, and antibiotic usage within the preceding 3 weeks was reported in 477 (58\%) children. Resistance to at least one antibiotic was detected in $95 \%$ of the isolates (401/421). Resistance to cotrimoxazole, tetracycline, phenoxymethylpenicillin, and erythromycin was $78 \%, 75 \%, 75 \%$, and $70 \%$, respectively. Low resistance for amoxicillin (4\%), benzylpenicillin (4\%), and cefotaxime ( $2 \%$ ) was observed. The intermediate resistance to amoxicillin was $32 \%$. Multidrug resistance was observed in $60 \%$. Coresistance to cotrimoxazole, tetracycline, and erythromycin was the most common pattern. The proportion of children with resistant bacteria was higher among the children in whom antibiotic usage was reported in the preceding 3 weeks. ${ }^{48}$

The rising prevalence of resistance to many of the currently used antibiotics and the problems encountered in treating serious bacterial infections stress the importance of using antibiotics judiciously and also the need to develop new agents.

\section{Ceftaroline}

Ceftaroline is a new cephalosporin that is administered parenterally. It was approved by the US Food and Drug Administration (FDA) in October 2010 for the treatment of cSSTIs (including those due to MRSA) and CAP. The EMA approved its use in Europe for the same indications in August 2012.

\section{Microbiology of ceftaroline}

Ceftaroline is active against gram-positive and gram-negative bacteria. Like other beta-lactams, it exerts its bactericidal activity by binding to penicillin-binding proteins (PBPs) resulting in inhibition of bacterial cell wall synthesis.

\section{Mechanism of action}

Ceftaroline binds to PBP 1-4 and has a higher affinity for PBP 2a (mecA), which confers resistance to methicillin. It binds to PBPs that are found in S. pneumoniae (PBP1A, 1B, 2X, 2A/B, and 3). ${ }^{49}$ The main binding site in Enterobacteriaceae is membrane PBPs and this leads to reactions which interfere with formation of the cell wall. ${ }^{50}$

The high affinity of ceftaroline (median inhibition concentration $\left[\mathrm{IC}_{50}\right], 0.9 \mathrm{mg} / \mathrm{L}$ ) for MRSA PBP 2a was demonstrated when compared with cefozopran $\left(\mathrm{IC}_{50}, 150 \mathrm{mg} / \mathrm{L}\right)$, another cephalosporin which is inactive against MRSA. ${ }^{51}$ The binding of ceftaroline to PBP 2a of the MRSA strain 67-0 with increased affinity was also confirmed in a study that compared ceftaroline with oxacillin and ceftriaxone. Ceftaroline showed a high affinity for PBP $2 \mathrm{a}\left(\mathrm{IC}_{50}, 0.16 \mathrm{mg} / \mathrm{L}\right)$ compared with oxacillin $\left(\mathrm{IC}_{50}, 408 \mathrm{mg} / \mathrm{L}\right)$ and ceftriaxone $\left(\mathrm{IC}_{50}, 677 \mathrm{mg} / \mathrm{L}\right){ }^{52}$ The activity of PBP $2 \mathrm{a}$ is inhibited more efficiently by ceftaroline than other beta-lactams. ${ }^{53}$

Ceftaroline showed very good PBP affinity against six $S$. aureus and seven $S$. pneumoniae isolates compared with ceftriaxone and cefotaxime. For penicillin-sensitive Streptococcus pneumoniae strains, ceftaroline affinities were in the order PBP2X and $-3>$ PBP1A, $-1 \mathrm{~B}$, and $-2 \mathrm{~A}>\mathrm{PBP} 2 \mathrm{~B}$, and ceftaroline had $\geq 2$-fold lower $\mathrm{IC}_{50} \mathrm{~s}(0.1-4 \mu \mathrm{g} / \mathrm{mL})$ for PBP2X, $-2 \mathrm{~A},-2 \mathrm{~B}$, and -3 than those for the other tested cephalosporins. In three Streptococcus pneumoniae isolates resistant to penicillin, ceftaroline had a high affinity for PBP2X ( $\mathrm{IC}_{50}$, $0.1-1 \mu \mathrm{g} / \mathrm{mL})$, PBP2B ( $\left.\mathrm{IC}_{50}, 0.5-4 \mu \mathrm{g} / \mathrm{mL}\right)$, and PBP1A ( $\mathrm{IC}_{50}$, $0.125-0.25 \mu \mathrm{g} / \mathrm{mL}$ ) sites for cephalosporin PBP binding activity. In MSSA strains, ceftaroline PBP affinities were higher or similar to those of the three other tested beta-lactams. In MRSA, ceftaroline bound to PBP2a $\left(\mathrm{IC}_{50}, 0.01-1 \mu \mathrm{g} / \mathrm{mL}\right)$ with up to 256 times greater affinity than those of other agents. ${ }^{49}$

\section{Microbiological activity}

Table 1 shows ceftaroline activity against MSSA and MRSA, with $90 \%$ of isolates having a minimum inhibitory concentration $\left(\mathrm{MIC}_{90}\right.$ ) of 0.25 (MIC range $0.03-0.5$ ) and $1 \mathrm{mg} / \mathrm{L}$ (MIC range 0.5-2), respectively. Ceftaroline also retains in vitro potency against $S$. aureus strains with decreased vancomycin susceptibility $\left(\mathrm{MIC}_{90}, 2 \mathrm{mg} / \mathrm{L}\right)$ or linezolid susceptibility $\left(\mathrm{MIC}_{90}, 2 \mathrm{mg} / \mathrm{L}\right)$. Streptococcus pyogenes and Streptococcus agalactiae were sensitive to ceftaroline, with MICs $\left(\mathrm{MIC}_{50}-\mathrm{MIC}_{90}\right)$ of $\leq 0.03 \mathrm{mg} / \mathrm{L}$. Ceftaroline activity against Enterococcus faecalis was limited, with $\mathrm{MIC}_{90} \mathrm{~s}$ of 4 and $8 \mathrm{mg} / \mathrm{L}$, respectively, for vancomycin-sensitive and vancomycin-resistant strains. Ceftaroline was active against S. pneumoniae, including strains that are resistant to penicillin 
Table I In vitro ceftaroline activity against common grampositive and gram-negative organisms

\begin{tabular}{ll}
\hline Organism & MIC range (mg/L) \\
\hline Staphylococcus aureus & \\
MSSA & $0.03-0.5$ \\
MRSA & $0.5-2$ \\
Vancomycin reduced susceptibility & $0.25-2$ \\
Linezolid non-susceptible & $0.5-2$ \\
Streptococcus pyogenes & $\leq 0.008-0.015$ \\
Streptococcus agalactiae & $\leq 0.008-0.03$ \\
Eneterococcus faecalis & \\
Vancomycin susceptible & $0.25-16$ \\
Vancomycin resistant & $0.5-16$ \\
Streptococcus pneumoniae & \\
Penicillin susceptible & $\leq 0.008-0.06$ \\
Penicillin intermediate & $\leq 0.008-0.12$ \\
Penicillin resistant & $0.03-0.5$ \\
Penicillin high-level resistant & $0.06-0.5$ \\
Levofloxacin non-susceptible & $\leq 0.008-0.5$ \\
Multidrug resistant & $\leq 0.008-0.5$ \\
Escherichia coli: ceftazidime susceptible & $0.015-8$ \\
Klebsiella pneumonia: ceftazidime susceptible & $0.015-1$ \\
Haemophilius influenzae & \\
$\beta$-lactamase negative & $\leq 0.008-0.25$ \\
$\beta$-lactamase positive & $\leq 0.008-0.12$ \\
Pseudomonas aeruginosa & 4 to $>16$ \\
Acinetobacter baumannii & 2 to $>16$ \\
\hline Note Bie D, Critchey IA, Riccosne TA, &
\end{tabular}

Note: Biek D, Critchley IA, Riccobene TA, Thye DA. Ceftaroline fosamil: a novel broad-spectrum cephalosporin with expanded anti-gram-positive activity. J Antimicrob Chemother. 2010;65(4):iv9-iv16, by permission of Oxford University Press. ${ }^{54}$

Abbreviations: MIC, minimum inhibitory concentration; MSSA, methicillin-sensitive Staphylococcus aureus; MRSA, methicillin-resistant Staphylococcus aureus.

and levofloxacin, and are multidrug-resistant (inhibition by $\leq 0.5 \mathrm{mg} / \mathrm{L}$ ). It has activity against Escherichia coli and Klebsiella pneumoniae isolates $\left(\mathrm{MIC}_{90} \mathrm{~s}, 0.25\right.$ and $0.5 \mathrm{mg} / \mathrm{L}$, respectively) which are sensitive to ceftazidime, and betalactamase positive and negative isolates of $H$. influenzae $\left(\mathrm{MIC}_{90} \mathrm{~s}, 0.03\right.$ and $0.015 \mathrm{mg} / \mathrm{L}$, respectively).

Ceftaroline has no activity against Enterobacteriaceae that produce extended spectrum beta-lactamase (ESBL) or are AmpC-overexpressers. Activity against gram-negative rods which are nonfermenters like $P$. aeruginosa and Acinetobacter baumannii is limited, with $\mathrm{MIC}_{90} \mathrm{~s}$ of $>16 \mathrm{mg} / \mathrm{L} .{ }^{54}$ Activity against Gram positive anaerobes is similar to that of amoxicillinclavulanate and is $4-8$ times higher than that of ceftriaxone. It has low activity against Bacteroides fragilis, but is active against beta-lactamase negative strains, including Actinomyces species, Propionibacterium, Eubacterium, and Clostridium species. ${ }^{55}$

An in vitro profiling of ceftaroline against clinical isolates from the US, demonstrated low ceftaroline MIC ranges against $S$. aureus, from $\leq 0.03$ to $1 \mu \mathrm{g} / \mathrm{mL}$ for MSSA and $0.12-2 \mu \mathrm{g} / \mathrm{mL}$ for MRSA. Ceftaroline activity was high against beta-haemolytic Streptococci, S. pneumoniae (regardless of penicillin-susceptibility status), H. influenza, and Moraxella catarrhalis (M. catarrhalis) (regardless of beta-lactamase activity). Activity against common gramnegative bacteria was sustained. ${ }^{56}$ This shows the potential that ceftaroline has as a wide-spectrum antimicrobial option in the management of HA- and CA-infections.

In an evaluation of ceftaroline activity against 14,169 isolates from patients with cSSTIs in the US and Europe, ceftaroline demonstrated activity against 2,254 US MRSA isolates $\left(\mathrm{MIC}_{90}, 1 \mathrm{mg} / \mathrm{L}\right)$ and against 734 European MRSA isolates $\left(\mathrm{MIC}_{90}, 2 \mathrm{mg} / \mathrm{L}\right)$. The $\mathrm{MIC}_{90}$ for MSSA was $0.25-0.5 \mathrm{mg} / \mathrm{L}$. Ceftaroline also showed activity against coagulase negative staphylococci $\left(\mathrm{MIC}_{90}, 0.5-1 \mathrm{mg} / \mathrm{L}\right.$ ), Enterococcus faecalis $\left(\mathrm{MIC}_{90}, 2 \mathrm{mg} / \mathrm{L}\right), \beta$-haemolytic streptococci $\left(\mathrm{MIC}_{90}, 0.015-0.03 \mathrm{mg} / \mathrm{L}\right)$, viridans group streptococci $\left(\mathrm{MIC}_{90}, 0.012-0.25 \mathrm{mg} / \mathrm{L}\right)$, and E. coli $\left(\mathrm{MIC}_{90}\right.$, $0.25-16 \mathrm{mg} / \mathrm{L}){ }^{26}$

In another evaluation of ceftaroline activity against isolates resistant to cefotaxime, ceftaroline had the greatest activity against 120 clinical isolates of cefotaxime-resistant S. pneumoniae, with MICs ranging from 0.125 to $2 \mu \mathrm{g} / \mathrm{mL}$; the $\mathrm{MIC}_{90}$ was $0.5 \mu \mathrm{g} / \mathrm{mL}$. A $S$. pneumoniae strain with a ceftaroline $\mathrm{MIC}_{90}$ of $2 \mu \mathrm{g} / \mathrm{mL}$ was resistant to cefotaxime and ceftriaxone (MICs $\geq 16 \mu \mathrm{g} / \mathrm{mL}$ ). Ceftaroline was 16 times more active in vitro than cefotaxime, penicillin, ceftriaxone, amoxicillin, and meropenem. Ceftaroline also showed potent activity against 18 laboratory isolates with PBP and murM mutations responsible for beta-lactam resistance. Ceftaroline MICs against these isolates ranged from 0.015 to $0.25 \mu \mathrm{g} / \mathrm{mL}$; the $\mathrm{MIC}_{90}$ was $0.03 \mu \mathrm{g} / \mathrm{mL}$, and the penicillin, ceftriaxone, and amoxicillin $\mathrm{MIC}_{90}$ s were $\geq 4 \mu \mathrm{g} / \mathrm{mL} .^{57}$

In an assessment of the in vitro activity of ceftaroline against 1,750 strains of $S$. pneumoniae from patients with various pneumococcal infections in 43 US medical centers during 2010-2011, all isolates were ceftaroline sensitive (using a breakpoint of $\leq 0.5 \mu \mathrm{g} / \mathrm{mL}$ ). Ceftaroline MICs were 16 times lower than ceftriaxone MICs. Around $38.9 \%$ of the isolates were resistant to penicillin and $9.1 \%$ were ceftriaxoneresistant. ${ }^{58}$ Table 2 displays ceftaroline and ceftriaxone MICs according to the penicillin susceptibility of the S. pneumoniae isolates. For parenteral penicillin, high-level penicillin resistance was detected in 6 isolates $(0.3 \%)$, with an MIC of $8 \mu \mathrm{g} / \mathrm{mL}$. Ceftaroline MICs of these 6 strains were $0.12 \mu \mathrm{g} /$ $\mathrm{mL}$ (1), $0.25 \mu \mathrm{g} / \mathrm{mL}$ (1) and $0.5 \mu \mathrm{g} / \mathrm{mL}$ (4) while ceftriaxone MICs were $2 \mu \mathrm{g} / \mathrm{mL}$ (2), $8 \mu \mathrm{g} / \mathrm{mL}$ (2) and $16 \mu \mathrm{g} / \mathrm{mL}$ (2). The number of isolates sensitive was 1,520 (86.9\%). Using the Clinical and Laboratory Standards Institute (CLSI) oral penicillin breakpoints, 1,066 isolates (60.9\%) demonstrated 
Table 2 In vitro activities of ceftaroline and ceftriaxone against I,750 isolates of Streptococcus pneumoniae according to penicillin susceptibility

\begin{tabular}{|c|c|c|c|c|c|c|c|c|}
\hline \multirow[t]{2}{*}{ Penicillin susceptibility } & \multirow{2}{*}{$\begin{array}{l}\text { Penicillin MIC } \\
(\mu \mathrm{g} / \mathrm{mL})\end{array}$} & \multirow{2}{*}{$\begin{array}{l}\text { No of } \\
\text { isolates }\end{array}$} & \multicolumn{3}{|c|}{ Ceftaroline MIC ( $\mu \mathrm{g} / \mathrm{mL})$} & \multicolumn{3}{|c|}{ Ceftriaxone MIC $(\mu \mathrm{g} / \mathrm{mL})$} \\
\hline & & & $\mathrm{MIC}_{50}$ & $\mathrm{MIC}_{90}$ & Range & $\mathrm{MIC}_{50}$ & $\mathrm{MIC}_{90}$ & Range \\
\hline \multicolumn{9}{|l|}{ Oral } \\
\hline Susceptible & $<0.06$ & 1,066 & 0.008 & 0.008 & $<0.008-0.06$ & 0.03 & 0.06 & $<0.008-0.5$ \\
\hline Intermediate & $0.12-1$ & 352 & 0.03 & 0.06 & $<0.008-0.25$ & 0.25 & 1 & $<0.03-8$ \\
\hline Resistant & $>2$ & 332 & 0.2 & 0.25 & 1 & I & 4 & $0.5-16$ \\
\hline \multicolumn{9}{|l|}{ Parenteral administration } \\
\hline Susceptible & $<2$ & 1,520 & 0.008 & 0.06 & $<0.008-0.25$ & 0.06 & 0.5 & $<0.008-8$ \\
\hline Intermediate & 4 & 224 & 0.12 & 0.25 & $<0.008-0.5$ & 2 & 4 & $0.5-16$ \\
\hline Resistant & $>8$ & 6 & - & - & - & - & - & - \\
\hline
\end{tabular}

Note: @ Antimicrob. Agents Chemother, 2012;56(6):3406-3408. Reproduced with permission from American Society for Microbioloty. ${ }^{58}$

Abbreviation: MIC, minimum inhibitory concentration.

penicillin susceptibility, $352(20.1 \%)$ were classified as intermediate, and 332 (19.0\%) showed penicillin resistance. ${ }^{58}$ This suggests that ceftaroline is an effective alternative for the management of infections due to $S$. pneumoniae strains that are not susceptible to antibiotics in current use.

\section{Pharmacology of ceftaroline}

Ceftaroline fosamil is a prodrug which is converted to active ceftaroline by plasma phosphatases after IV administration. $^{54}$

\section{Chemical structure}

Ceftaroline has an ethoxyiminoacetamido group in the C-7 moiety and a thio 5-membered heteroaromatic spacer group at position 3. It is water-soluble, has good chemical stability and a molecular weight of $762 . .^{55}$

\section{Pharmacokinetics}

Ceftaroline exhibited dose-proportional pharmacokinetics (PK) after IV administration of 300 or $600 \mathrm{mg} 12$ hourly for
14 days or $800 \mathrm{mg}$ daily for 7 days, with a $t^{1 / 2}$ of 2.6 hours (Table 3). ${ }^{54}$ After administration of $600 \mathrm{mg}$ of IV ceftaroline 12 hourly for 14 days, PK studies demonstrated area under the curve (AUC) values of 56.8 and $56.2 \mathrm{mg} \cdot \mathrm{h} / \mathrm{L}$ post initial and final dose, respectively, ${ }^{54}$ indicating that multiple dosing does not lead to drug accumulation.

One-hour IV infusion of $600 \mathrm{mg}$ of ceftaroline leads to maximum serum concentrations $\left(C_{\max }\right)$ of $\sim 20 \mathrm{mg} / \mathrm{L}$. A similar dose administered intramuscularly leads to a $C_{\max }$ of $8.5 \mathrm{mg} / \mathrm{L}$ at 2 hours. ${ }^{59}$ A single dose of ceftaroline has a serum $t^{1} / 2$ of 1.6 hours while multiple doses lead to $t^{1 / 2}$ of 2.7 hours. Like other parenteral cephalosporins, the volume of distribution $\left(V_{\mathrm{d}}\right)$ is $\sim 20 \mathrm{~L}$ and plasma protein binding is $\sim 20 \%$. $^{60}$

Metabolism of ceftaroline is through hydrolysis of its beta-lactam ring to produce an open-ring metabolite (ceftaroline M-1), which is not active. Elimination of ceftaroline and its metabolites is mainly through the renal route and is decreased in individuals with renal impairment. Ceftaroline dose needs to be adjusted if creatinine clearance

Table 3 PK parameters for ceftaroline after intravenous infusion over I hour, administered 12 or 24 hourly for 7-14 days

\begin{tabular}{|c|c|c|c|c|c|c|}
\hline & \multicolumn{6}{|c|}{ PK parameter } \\
\hline & $C_{\max }(\mathrm{mg} / \mathrm{L})$ & $t^{1 / 2,(h)}$ & $A \cup C_{0-\infty},(\mathrm{mg} \cdot \mathrm{h} / \mathrm{L})$ & $A \cup C_{0-\tau},(\mathrm{mg} \cdot \mathrm{h} / \mathrm{L})$ & $A e_{0-t},(\%$ dose $)$ & $\mathrm{CL}_{\mathrm{R}},(\mathrm{mL} / \mathrm{min})$ \\
\hline \multicolumn{7}{|c|}{$300 \mathrm{mg} 12$ hourly for 14 days } \\
\hline First dose & $9.98 \pm 0.76$ & $2.56 \pm 0.47$ & $25.8 \pm 3.84$ & & $51.4 \pm 36.8$ & $92.8 \pm 69.3$ \\
\hline Last dose & $8.55 \pm 1.85$ & $2.62 \pm 0.4 \mathrm{I}$ & & $24.3 \pm 3.66$ & $40.6 \pm 8.8$ & $75.3 \pm 19.9$ \\
\hline \multicolumn{7}{|c|}{$600 \mathrm{mg} 12$ hourly for 14 days } \\
\hline First dose & $|9.0 \pm 0.7|$ & $1.60 \pm 0.38$ & $56.8 \pm 9.31$ & & $42.1 \pm 9.8$ & $68.8 \pm 19.8$ \\
\hline Last dose & $21.3 \pm 4.10$ & $2.66 \pm 0.40$ & & $56.2 \pm 8.90$ & $73.9 \pm 45.9$ & $118.9 \pm 72.8$ \\
\hline \multicolumn{7}{|c|}{$800 \mathrm{mg} 24$ hourly for 7 days } \\
\hline First dose & $29.7 \pm 4.97$ & $2.16 \pm 0.15$ & $72.4 \pm 8.66$ & & $45.7 \pm 9.1$ & $78.0 \pm 23.2$ \\
\hline Last dose & $31.5 \pm 2.39$ & $2.63 \pm 0.24$ & & $74.2 \pm 14.2$ & $40.1 \pm 8.9$ & $66.1 \pm 20.2$ \\
\hline
\end{tabular}

Notes: Values presented are arithmetic means. Biek D, Critchley IA, Riccobene TA, Thye DA. Ceftaroline fosamil: a novel broad-spectrum cephalosporin with expanded anti-gram-positive activity. J Antimicrob Chemother. 2010;65(4):iv9-iv16, by permission of Oxford University Press. ${ }^{54}$

Abbreviations: PK, pharmacokinetics; $A e_{0-\imath}$ cumulative amount of unchanged drug excreted into the urine from time 0 to time $t$; $A \cup C_{0-\infty}$, area under the plasma concentration versus time curve from time 0 to infinity; $A \cup C_{0-\tau}$, area under the plasma concentration versus time curve during the dosing interval $(t)$; $C L_{R}$, renal clearance of the drug from plasma; $C_{\max }$, maximum plasma drug concentration; NA, not applicable; $t^{1 / 2}$, terminal elimination half-life. 
is $\leq 50 \mathrm{~mL} / \mathrm{min}$. Elimination of ceftaroline is not affected by impaired liver function..$^{55}$

\section{Pharmacodynamics}

The primary pharmacodynamics (PD) parameter to determine efficacy is the proportion of time the concentration of free drug is greater than the MIC (fT > MIC). In an evaluation of in vivo PD of ceftaroline, thighs of neutropenic mice were infected with five strains of $S$. pneumoniae and four strains of $S$. aureus, and treated with $0.1-100 \mathrm{mg} / \mathrm{kg}$ ceftaroline 6 hourly. Ceftaroline MICs for these strains ranged from 0.008 to $1 \mathrm{mg} / \mathrm{L}$. The $\mathrm{fT}>\mathrm{MIC}$ resulting in a static response ranged from $26 \% \pm 8 \%$ for $S$. aureus to $39 \% \pm 9 \%$ for $S$. pneumoniae. ${ }^{54}$

The probability of target attainment (PTA) is the probability that a specific value of a pharmacodynamic index is attained at a particular MIC. ${ }^{61}$ MICs of 1 and $2 \mathrm{mg} / \mathrm{L}$ were chosen for the PTA analyses after MICs of key microorganisms were analyzed. Based on Monte Carlo simulations of 12 hourly $600 \mathrm{mg}$ of ceftaroline with a 1 hour infusion, the mean $\mathrm{fT}>$ MICs that were above an MIC of 1 and $2 \mathrm{mg} / \mathrm{L}$ were $71 \%$ and $51 \%$ of the dosing interval, respectively. The Monte Carlo-simulated predicted PTAs for an MIC of 1 and $2 \mathrm{mg} / \mathrm{L}$ were $100 \%$ and $90 \%$, respectively, for the $40 \% \mathrm{fT}$ $>$ MIC target. ${ }^{54}$

In a pharmacodynamics study of ceftaroline against 12 S. aureus isolates (3 MSSA and 9 MRSA), three of which had a vancomycin-intermediate phenotype, ceftaroline demonstrated 2.5 - to $4.0-\log _{10}$-unit decreases in viable counts by 24 hours with all strains and a 0.5 - to $4.0-\log$-unit decrease in counts at 96 hours. In dose-ranging studies, the fT $>$ MIC of $24.5 \% \pm 8.9 \%$ produced a 24 -hour bacteriostatic effect, one of $27.8 \% \pm 9.5 \%$ caused a $-1-\log$-unit drop, and one of $32.1 \% \pm 8.1 \%$ led to a $-2-\log$-unit drop. The fT $>$ MIC values for MSSA and MRSA isolates were similar and they rose with rising duration of exposure up to 96 hours. fT $>$ MICs of $<50 \%$ led to growth on 4 times MIC recovery plates at 96 hours after exposure to the drug. Therefore, a pharmacodynamic index target can be achieved with fT $>$ MIC of $25 \%-30 \%$. To prevent development of resistance, $\mathrm{fT}>\mathrm{MIC}$ values should be $>50 \% .{ }^{62}$

\section{Efficacy and comparative studies}

The efficacy of ceftaroline in patients was initially observed in a Phase II proof of concept trial which compared the safety and efficacy of ceftaroline with standard therapy (vancomycin with or without aztreonam) in treating cSSTI. Around 88 of 100 enrolled subjects were clinically evaluable (CE) and the clinical cure rate was $96.7 \%(59 / 61)$ for ceftaroline and $88.9 \%$ (24/27) for standard therapy. The microbiological success rate was $95.2 \%$ (40/42) for ceftaroline and $85.7 \%$ $(18 / 21)$ for standard therapy. ${ }^{63}$

The CeftAroliNe Versus VAncomycin in Skin and Skin Structure Infections (CANVAS) Phase III study confirmed the efficacy and safety of ceftaroline. The study was randomized, double-blind, active-controlled and it was carried out across several centers in different countries. It comprised of two parallel, methodologically similar trials (CANVAS 1 and CANVAS 2) whose primary objective was to ascertain the noninferiority in the clinical cure rate achieved with ceftaroline in comparison with that achieved with vancomycin and aztreonam at the test-of-cure (TOC) visit in the CE and modified intent-to-treat (MITT) patient groups. Both trials included patients $\geq 18$ years of age and who had a cSSTI that required 5 days or more of parenteral antimicrobial treatment. The main outcome was clinical cure, described as resolution of clinical features of cSSTI or improved status requiring no further antibiotic therapy ${ }^{64}$

The CANVAS 1 trial enrolled 702 patients, ceftaroline $600 \mathrm{mg}$ was administered 12 hourly to 353 subjects while vancomycin $1 \mathrm{~g}$ and aztreonam $1 \mathrm{~g}$ were given 12 hourly to the remaining 349 subjects for $5-14$ days. At the TOC visit (8-15 days post final antibiotic dose), cure rates in both treatment groups across all study populations were comparable (Table 4). Similar clinical cure rates were observed for ceftaroline, and vancomycin and aztreonam in the CE $(91.1 \%, 288 / 316$ versus $93.3 \%, 280 / 300$; difference in cure rates, $-2.2 ; 95 \% \mathrm{CI}$ [confidence interval], -6.6, 2.1) and MITT $(86.6 \%, 304 / 351$ versus $85.6 \%, 297 / 347$; difference in cure rates, 1; 95\% CI, $-4.2,6.2)$ populations, respectively. For MRSA cSSTIs, the clinical cure rate was $95.1 \%$ (78/82) for ceftaroline and $95.2 \%(59 / 62)$ for vancomycin and aztreonam. Similar cure rates were observed in individuals with MSSA $(91.3 \%$ for ceftaroline and $94.6 \%$ for vancomycin and aztreonam) and in those from whom gram-negative bacteria were isolated. ${ }^{64}$

The CANVAS 2 study demonstrated similar cure rates and safety profile in the group treated with ceftaroline. Out of the 694 patients enrolled, 348 were given ceftaroline while 346 received vancomycin and aztreonam. Similar clinical cure rates were observed for the ceftaroline, and vancomycin and aztreonam groups in the CE (92.2\% versus $92.1 \%)$ and MITT (85.1\% versus $85.5 \%$ ) populations, respectively (Table 4). ${ }^{65}$

The integrated analysis of CANVAS 1 and 2, demonstrated similar clinical cure rates for ceftaroline, and vancomycin and aztreonam in the CE (91.6\% versus $92.7 \%)$ 
Table 4 Clinical cure rates (\%) by study population in CANVAS trials

\begin{tabular}{llll}
\hline Study & \multicolumn{2}{l}{ Study population } & ME \\
\cline { 2 - 4 } & CE & & MITT \\
\hline CANVAS I & & 92.2 & 86.6 \\
$\quad$ Ceftaroline & 91.1 & 94.7 & 85.6 \\
$\quad$ Vancomycin plus aztreonam & 93.3 & $-2.5(-7.2,2.1)$ & $1.0(-4.2,6.2)$ \\
$\quad$ Difference in cure rates, \% $(95 \% \mathrm{Cl})$ & $-2.2(-6.6,2.1)$ & 92.9 & 85.1 \\
CANVAS 2 & 92.2 & 95.0 & 85.5 \\
$\quad$ Ceftaroline & 92.1 & $-2.1(-6.9,2.5)$ & $-0.4(-5.8,5.0)$ \\
$\quad$ Vancomycin plus aztreonam & $0.1(-4.4,4.5)$ & 92.7 & 85.9 \\
$\quad$ Difference in cure rates, \% $(95 \% \mathrm{Cl})$ & & 91.6 & 85.5 \\
Integrated CANVAS I and 2 & 91.6 & $-1.7(-4.9,1.6)$ & $0.3(-3.4,4.0)$ \\
$\quad$ Ceftaroline & 92.7 & $-1.1(-4.2,2.0)$ & \\
$\quad$ Vancomycin plus aztreonam & & \\
Difference in cure rates, \% $(95 \% \mathrm{Cl})$ &
\end{tabular}

Notes: Corey GR, Wilcox MH, Talbot GH, Thye D, Friedland D, Baculik T. CANVAS I: the first Phase III, randomized, double-blind study evaluating ceftaroline fosamil for the treatment of patients with complicated skin and skin structure infections. J Antimicrob Chemother. 2010;65(Suppl 4):iv4 I-iv5I, by permission of Oxford University Press. ${ }^{64}$ Wilcox MH, Corey GR, Talbot GH, et al. CANVAS 2: the second Phase III, randomized, double-blind study evaluating ceftaroline fosamil for the treatment of patients with complicated skin and skin structure infections. J Antimicrob Chemother. 2010;65(Suppl 4):iv53-iv65, by permission of Oxford University Press. ${ }^{65}$ Corey GR, Wilcox M, Talbot $\mathrm{GH}$, et al. Integrated analysis of CANVAS I and 2: Phase 3, multicenter, randomized, double-blind studies to evaluate the safety and efficacy of ceftaroline versus vancomycin plus aztreonam in complicated skin and skin-structure infection. Clin Infect Dis. 2010;5I (6):64I-650, by permission of Oxford University Press. ${ }^{66}$

Abbreviations: CANVAS, ceftaroline versus $v$ ancomycin in skin and skin structure infections; CE, clinically evaluable; ME, microbiologically evaluable; MITT, modified intent-to-treat; $\mathrm{Cl}$, confidence interval.

and MITT (85.9\% versus $85.5 \%$ ) populations, respectively (Table 4). The main study aim of noninferiority in the clinical cure rate for ceftaroline compared with vancomycin and aztreonam was met by both trials. Ceftaroline and vancomycin plus aztreonam has similar efficacy against polymicrobial and monomicrobial infections (Table 5). Table 6 shows the MIC ranges for isolates from primary infection sites and Table 7 presents clinical cure rates according to underlying microorganism. Clinical cure rates for subgroups of subjects with diabetes mellitus (for ceftaroline, $87.3 \%$; for vancomycin plus aztreonam, 90.9\%) and peripheral vascular disease (for ceftaroline, $88.9 \%$; for vancomycin plus aztreonam, 89.3\%) were similar (Table 8). Forty-seven patients with bacteremia had clinical cure rates of $84.6 \%$ for ceftaroline compared with $100 \%$ for vancomycin plus aztreonam. There were more cases of staphylococcal bacteremia in the ceftaroline group than the vancomycin plus aztreonam group (18 versus 9 , respectively).
Clinical failure was observed in 4 of the 26 patients in the ceftaroline-treated bacteremia group. Two were due to an adverse event (Clostridium difficile-associated diarrhea and allergic reaction), one required surgical intervention, and one had copathogen which was resistant ( $P$. aeruginosa). At the late follow-up visit, clinical relapse was observed in $1.1 \%$ (6 of 559) of subjects in the CE ceftaroline group, in comparison with $0.9 \%$ (5 of 549) of CE subjects in the vancomycin and aztreonam group. Microbiological response observed in $92.3 \%$ (432 of 468) of subjects in the ceftaroline group, versus $93.7 \%$ (418 of 446 ) of subjects in the vancomycin and aztreonam group was favorable. ${ }^{66}$

FDA recommendation that trials should include evaluation of clinical response at 48-72 hours after starting antibiotic treatment as the primary endpoint is based on data which indicate that termination of lesion spread and absence of fever in patients with skin infection is a reflection of

Table 5 Integrated CANVAS I and 2: clinical cure rates by infection type at the test-of-cure visit

\begin{tabular}{llll}
\hline Type of infection & Cure rate (\%) & & \\
\cline { 2 - 4 } & Ceftaroline & Vancomycin plus aztreonam & Difference, (\%) (95\% Cl) \\
\hline Microbiologically evaluable & $434 / 468(92.7)$ & $421 / 446(94.4)$ & $-1.7(-4.9$ to 1.6$)$ \\
Gram positive only & $348 / 37 I(93.8)$ & $330 / 350(94.3)$ & $-0.5(-4.1$ to 3.1$)$ \\
Gram negative only & $9 / 34(85.3)$ & $24 / 24(100)$ & $-15.6(-31.6$ to -1.2$)$ \\
Mixed gram positive and negative & $57 / 63(90.5)$ & $67 / 72(93.1)$ & $-2.6(-13.4$ to 7.2$)$ \\
Polymicrobial infection & $125 / 136(91.9)$ & $134 / 139(96.4)$ & $-4.2(-10.5$ to 1.5$)$ \\
\hline
\end{tabular}

Note: Corey GR, Wilcox M, Talbot GH, et al. Integrated analysis of CANVAS I and 2: Phase 3, multicenter, randomized, double-blind studies to evaluate the safety and efficacy of ceftaroline versus vancomycin plus aztreonam in complicated skin and skin-structure infection. Clin Infect Dis. 2010;51(6):64I-650, by permission of Oxford University Press. ${ }^{66}$

Abbreviation: CANVAS, ceftaroline versus v ancomycin in skin and skin structure infections; $\mathrm{Cl}$, confidence interval. 
Table 6 Integrated CANVAS I and 2: MIC ranges for selected isolates from the primary infection site (ME population)

\begin{tabular}{|c|c|c|c|c|}
\hline \multirow[t]{2}{*}{ Organism } & \multirow[t]{2}{*}{ No of isolates } & \multicolumn{3}{|l|}{ Ceftaroline } \\
\hline & & MIC range $(\mu \mathrm{g} / \mathrm{mL})$ & No of isolates & MIC range $(\mu \mathrm{g} / \mathrm{mL})$ \\
\hline Gram positive pathogens & & & & Vancomycin \\
\hline Staphylococcus aureus & 377 & 0.06 to 2 & 357 & $\leq 0.25$ to 2 \\
\hline MRSA & 150 & 0.25 to 2 & 121 & 0.5 to 2 \\
\hline MSSA & 227 & 0.06 to 0.5 & 236 & $\leq 0.25$ to 2 \\
\hline Streptococcus pyogenes & 55 & $\leq 0.004$ to 0.008 & 58 & 0.25 to 1 \\
\hline Streptococcus agalactiae & 20 & 0.008 to 0.015 & 18 & 0.25 to 0.5 \\
\hline Enterococcus faecalis & 25 & 0.25 to 16 & 24 & 0.5 to 2 \\
\hline Gram negative pathogens & & & & Aztreonam \\
\hline Pseudomonas aeruginosa & 16 & 4 to $>16$ & 18 & I to $>32$ \\
\hline Escherichia coli & 21 & 0.015 to $>16$ & 21 & $\leq 0.03$ to 0.5 \\
\hline Klebsiella pneumoniae & 18 & 0.03 to $>16$ & 14 & $\leq 0.03$ to $>32$ \\
\hline Proteus mirabilis & 15 & $\leq 0.008$ to $>16$ & 21 & $\leq 0.03$ to 16 \\
\hline
\end{tabular}

Note: Corey GR, Wilcox M, Talbot GH, et al. Integrated analysis of CANVAS I and 2: Phase 3, multicenter, randomized, double-blind studies to evaluate the safety and efficacy of ceftaroline versus vancomycin plus aztreonam in complicated skin and skin-structure infection. Clin Infect Dis. 20I0;5I(6):64I-650, by permission of Oxford University Press. ${ }^{66}$

Abbreviations: CANVAS, ceftaroline versus $v$ ancomycin in skin and skin structure infections; MIC, minimum inhibitory concentration; ME, microbiologically evaluable; MRSA, methicillin-resistant Staphylococcus aureus; MSSA, methicillin-sensitive Staphylococcus aureus.

maximum antimicrobial treatment effect after 48-72 hours of antibacterial treatment. ${ }^{67}$ The CANVAS studies also gathered data which were relevant in the analysis of clinical response rates at day 3 , and therefore a retrospective analysis was carried out in subjects with a lesion size of $\geq 75 \mathrm{~cm}^{2}$ and extensive cellulitis, major abscess, or wound infection. Integrated CANVAS clinical response rates at day 3 were $74.0 \%$ for ceftaroline and $66.2 \%$ for vancomycin and aztreonam (difference, 7.8\%; 95\% CI, 1.3\%-14.0\%). Absolute treatment differences in favor of ceftaroline of $9.4 \%$ (CANVAS 1) and 5.9\% (CANVAS 2) were observed. For cSSTI caused by MRSA, response rates were $81.7 \%$ and $77.4 \%$ in the ceftaroline, and vancomycin and aztreonam groups, respectively. Ceftaroline had a numerically greater clinical response than vancomycin plus aztreonam at day 3 of therapy in cSSTI. ${ }^{67}$

The ceFtarOline Community-acquired pneUmonia trial versuS ceftriaxone (FOCUS) studies were Phase III, doubleblinded, randomized, multinational, multicenter trials that compared the efficacy and safety of ceftaroline with ceftriaxone given IV for 5-7 days in hospitalized adult patients with CAP. The main aim of the studies was to ascertain the noninferiority of ceftaroline in the clinical cure rates in comparison with those of ceftriaxone noted at the TOC visit in the CE and modified intent-to-treat efficacy (MITTE) populations. ${ }^{68}$

Table 7 Integrated CANVAS I and 2: clinical cure rates for selected baseline isolates at the test-of-cure visit

\begin{tabular}{|c|c|c|c|c|}
\hline \multirow[t]{3}{*}{ Organism } & \multicolumn{4}{|c|}{ Clinical cure rate (\%) } \\
\hline & \multicolumn{2}{|c|}{ Isolates in ME population } & \multicolumn{2}{|c|}{ Isolates in mMITT population } \\
\hline & Ceftaroline & Vancomycin plus aztreonam & Ceftaroline & Vancomycin plus aztreonam \\
\hline Staphylococcus aureus & 93.1 & 94.4 & 88.7 & 87.0 \\
\hline MRSA & 93.4 & 94.3 & 86.6 & 82.1 \\
\hline MSSA & 93.0 & 94.5 & 90.2 & 90.3 \\
\hline Streptococcus pyogenes & 100 & 96.6 & 88.9 & 91.9 \\
\hline Streptococcus agalactiae & 95.5 & 100 & 92.6 & 90.5 \\
\hline Enterococcus faecalis & 80.0 & 91.7 & 71.4 & 82.1 \\
\hline Escherichia coli & 95.2 & 90.5 & 91.3 & 90.5 \\
\hline Pseudomonas aeruginosa & NA & NA & 80.0 & 88.0 \\
\hline Proteus mirabilis & 66.7 & 95.2 & 68.8 & 87.0 \\
\hline Klebsiella pneumoniae & 94.4 & 92.9 & 94.4 & 73.7 \\
\hline
\end{tabular}

Note: Corey GR, Wilcox M, Talbot GH, et al. Integrated analysis of CANVAS I and 2: Phase 3, multicenter, randomized, double-blind studies to evaluate the safety and efficacy of ceftaroline versus vancomycin plus aztreonam in complicated skin and skin-structure infection. Clin Infect Dis. 20I0;5I(6):64I-650, by permission of Oxford University Press. ${ }^{66}$

Abreviations: CANVAS, ceftaroline versus v ancomycin in skin and skin structure infections; ME, medically evaluable; mMITT, microbiological modified intent-to-treat; MRSA, methicillin-resistant Staphylococcus aureus; MSSA, methicillin-sensitive Staphylococcus aureus; NA, not applicable. 
Table 8 Integrated CANVAS I and 2: clinical cure rates by infection type, underlying comorbidity and bacteremia status (CE population) at the test-of-cure visit

\begin{tabular}{|c|c|c|c|}
\hline \multirow[t]{2}{*}{ Clinical diagnosis } & \multicolumn{3}{|c|}{ Clinical cure rate (\%) } \\
\hline & Ceftaroline & Vancomycin plus aztreonam & Difference, $(\%)(95 \% \mathrm{Cl})$ \\
\hline Cellulitis & 93.0 & 91.4 & $1.7(-3.4$ to 6.7$)$ \\
\hline Major abscess & 91.1 & 94.1 & $-3.0(-8.5$ to 2.3$)$ \\
\hline Infected wound & 86.9 & 89.0 & $-2.2(-12.8$ to 8.7$)$ \\
\hline Infected ulcer & 90.6 & 94.0 & $-3.5(-15.7$ to 8.3$)$ \\
\hline Infected burn & 100 & 100 & $0.0(-13.6$ to 17.9$)$ \\
\hline Infected bite & 100 & 100 & 0.0 \\
\hline Other & 80.0 & 100 & -20.0 \\
\hline \multicolumn{4}{|l|}{ Underlying comorbidity } \\
\hline Diabetes mellitus & 87.3 & 90.9 & $-3.5(-12.2$ to 5.0$)$ \\
\hline Peripheral vascular disease & 88.9 & 89.3 & $-0.2(-10.0$ to 9.7$)$ \\
\hline Bacteremia & 84.6 & 100 & $-15.4(-33.8$ to 1.5$)$ \\
\hline Staphylococcus aureus & 88.9 & 100 & $-11.1(-33.2$ to 5.7$)$ \\
\hline MRSA & 85.7 & 100 & $-14.3(-53.5$ to 58.4$)$ \\
\hline
\end{tabular}

Note: Corey GR, Wilcox M, Talbot GH, et al. Integrated analysis of CANVAS I and 2: Phase 3, multicenter, randomized, double-blind studies to evaluate the safety and efficacy of ceftaroline versus vancomycin plus aztreonam in complicated skin and skin-structure infection. Clin Infect Dis. 20I0;5I(6):64I-650, by permission of Oxford University Press. ${ }^{66}$

Abbreviations: CANVAS, ceftaroline versus v ancomycin in skin and skin structure infections; CE, clinically evaluable; Cl, confidence interval; MRSA, methicillin-resistant Staphylococcus aureus.

The FOCUS 1 study enrolled 613 patients, of which 298 received ceftaroline and 308 received ceftriaxone. Clinical cure rates in the CE population were $86.6 \%(194 / 224)$ for ceftaroline and $78.2 \%$ (183/234) for ceftriaxone (difference $8.4 \%$; $95 \% \mathrm{CI}, 1.4 \%-15.4 \%$ ); and in the MITTE population, $83.8 \%$ (244/291) for ceftaroline and $77.7 \%(233 / 300)$ for ceftriaxone (difference $6.2 \%$; $95 \% \mathrm{CI},-0.2 \%$ to $12.6 \%$ ) (Table 9). For CAP due to S. pneumoniae, clinical cure rates in the microbiological MITTE (mMITTE) population were $88.9 \%(24 / 27)$ and $66.7 \%(20 / 30)$ for ceftaroline and ceftriaxone, respectively (Table 10). ${ }^{68}$

The FOCUS 2 trial enrolled 627 subjects, of whom 315 were given ceftaroline and 307 were given ceftriaxone. Clinical cure rates in the CE population were $82.1 \%(193 / 235)$ for ceftaroline and $77.2 \%$ (166/215) for ceftriaxone (difference $4.9 \% ; 95 \% \mathrm{CI},-2.5 \%$ to $12.5 \%$ ); and in the MITTE population were $81.3 \%$ (235/289) for ceftaroline and $75.5 \%$ (206/273) for ceftriaxone (difference 5.9\%; 95\% CI, $-1.0 \%$

Table 9 FOCUS trials: clinical cure rates by study population at the test-of-cure visit

\begin{tabular}{|c|c|c|c|c|}
\hline & \multicolumn{4}{|l|}{ Study population } \\
\hline & CE & MITTE & ME & mMITTE \\
\hline \multicolumn{5}{|l|}{ FOCUS I (\%) } \\
\hline Ceftaroline & 86.6 & 83.8 & 89.9 & 88.0 \\
\hline Ceftriaxone & 78.2 & 77.7 & 76.1 & 75.0 \\
\hline Difference, \% (95\% Cl) & $8.4(1.4-15.4)$ & $6.2(-0.2$ to 12.6$)$ & I3.8 (1.3-26.4) & $13.0(0.7-25.2)$ \\
\hline \multicolumn{5}{|l|}{ FOCUS 2 (\%) } \\
\hline Ceftaroline & 82.1 & 81.3 & 81.2 & 80.0 \\
\hline Ceftriaxone & 77.2 & 75.5 & 75.0 & 75.0 \\
\hline Difference, \% (95\% Cl) & $4.9(-2.5$ to 12.5$)$ & $5.9(-1.0$ to 12.7$)$ & $6.2(-6.7$ to 19.2) & $5.0(-7.4$ to 17.4$)$ \\
\hline \multicolumn{5}{|l|}{ Integrated FOCUS (\%) } \\
\hline Ceftaroline & 84.3 & 82.6 & 85.1 & 83.6 \\
\hline Ceftriaxone & 77.7 & 76.6 & 75.5 & 75.0 \\
\hline Difference, \% (95\% Cl) & 6.7 (1.6-II.8) & $6.0(1.4-10.7)$ & $9.7(0.7-18.8)$ & $8.7(-0.0$ to 17.4$)$ \\
\hline
\end{tabular}

Notes: File JM Jr, Low DE, Eckburg PB, et al. FOCUS I: a randomized, double-blinded, multicentre, Phase III trial of the efficacy and safety of ceftaroline fosamil versus ceftriaxone in community-acquired pneumonia. J Antimicrob Chemother. 20I I;66(Suppl 3):iii I 9-iii32, by permission of Oxford University Press. ${ }^{68}$ Low DE, File TM Jr, Eckburg PB, et al. FOCUS 2: a randomized, double-blinded, multicentre, Phase III trial of the efficacy and safety of ceftaroline fosamil versus ceftriaxone in community-acquired pneumonia. J Antimicrob Chemother. 20I I;66(Suppl 3):iii33-iii44, by permission of Oxford University Press. ${ }^{69}$ File TM Jr, Low DE, Eckburg PB, et al. Integrated analysis of FOCUS I and FOCUS 2: randomized, doubled-blinded, multicenter phase 3 trials of the efficacy and safety of ceftaroline fosamil versus ceftriaxone in patients with community-acquired pneumonia. Clin Infect Dis. 2010;5 I(12): 1395-1405, by permission of Oxford University Press. ${ }^{70}$

Abbreviations: $\mathrm{Cl}$, confidence interval; $\mathrm{CE}$, clinically evaluable; FOCUS, ceftaroline community-acquired pneumonia trial versus ceftriaxone; MITTE, modified intent-totreat; ME, microbiologically evaluable; mMITTE, microbiological MITTE. 
Table 10 FOCUS trials: clinical cure rates by the most common baseline organisms at test-of-cure visit, in the microbiological modified intent-to-treat efficacy population

\begin{tabular}{|c|c|c|c|c|c|c|}
\hline \multirow[t]{3}{*}{ Organism } & \multicolumn{6}{|c|}{ Clinical cure rate (\%) } \\
\hline & \multicolumn{2}{|l|}{ FOCUS I } & \multicolumn{2}{|l|}{ FOCUS 2} & \multicolumn{2}{|c|}{ Integrated FOCUS } \\
\hline & Ceftaroline & Ceftriaxone & Ceftaroline & Ceftriaxone & Ceftaroline & Ceftriaxone \\
\hline \multicolumn{7}{|l|}{ Gram-positive bacteria } \\
\hline Streptococcus pneumonia & 88.9 & 66.7 & 83.3 & 70.0 & 85.5 & 68.6 \\
\hline MDRSP & 100 & 0 & 100 & 25.0 & 100 & 22.2 \\
\hline Staphylococcus aureus & 80.0 & 64.3 & 66.7 & 56.3 & 72.0 & 60.0 \\
\hline MRSA & NA & 0 & NA & 100 & NA & 50.0 \\
\hline \multicolumn{7}{|l|}{ Gram-negative bacteria } \\
\hline Haemophilius influenzae & 80.0 & 70.0 & 86.7 & 92.9 & 85.0 & 83.3 \\
\hline Haemophilius parainfluenzae & 87.5 & 90.0 & 100 & 75.0 & 94.1 & 83.3 \\
\hline Klebsiella pneumoniae & 87.5 & 60.0 & 100 & 87.5 & 93.3 & 76.9 \\
\hline Escherichia coli & 100 & 71.4 & 50.0 & 66.7 & 83.3 & 69.2 \\
\hline
\end{tabular}

Notes: File JM Jr, Low DE, Eckburg PB, et al. FOCUS I: a randomized, double-blinded, multicentre, Phase III trial of the efficacy and safety of ceftaroline fosamil versus ceftriaxone in community-acquired pneumonia. J Antimicrob Chemother. 201 I;66(Suppl 3):iii I9-iii32, by permission of Oxford University Press. ${ }^{68}$ Low DE, File TM Jr, Eckburg PB, et al. FOCUS 2: a randomized, double-blinded, multicentre, Phase III trial of the efficacy and safety of ceftaroline fosamil versus ceftriaxone in community-acquired pneumonia. J Antimicrob Chemother. 20 I 1;66(Suppl 3):iii33-iii44, by permission of Oxford University Press. ${ }^{69}$ File TM Jr, Low DE, Eckburg PB, et al. Integrated analysis of FOCUS I and FOCUS 2: randomized, doubled-blinded, multicenter phase 3 trials of the efficacy and safety of ceftaroline fosamil versus ceftriaxone in patients with community-acquired pneumonia. Clin Infect Dis. 2010;5I(12):1395-1405, by permission of Oxford University Press. ${ }^{70}$

Abbreviations: FOCUS, ceftaroline community-acquired pneumonia trial versus ceftriaxone; MDRSP, multidrug resistant Streptococcus pneumoniae; MRSA, methicillinresistant Staphylococcus aureus; NA, not applicable.

to $12.7 \%$ ) (Table 9). For CAP due to S. pneumoniae, clinical cure rates in the mMITTE population were $83.3 \%(35 / 42)$ and $70.0 \%(28 / 40)$ for ceftaroline and ceftriaxone, respectively (Table 10). ${ }^{69}$

The integrated analysis of FOCUS 1 and 2 demonstrated a clinical cure of $84.3 \%$ in the CE subjects treated with ceftaroline while that of $77.7 \%$ was observed in the ceftriaxonetreated subjects (difference, 6.7\%; 95\% CI, 1.6\%-11.8\%). In the MITTE population, clinical cure rates were $82.6 \%$ for ceftaroline and $76.6 \%$ for ceftriaxone (difference, $6.0 \%$; 95\% CI, 1.4\%-10.7\%) (Table 9). Clinical cure rates in the ME population for $S$. pneumoniae, multidrug resistant Streptococcus pneumoniae (MDRSP), and S. aureus were $85.7 \%$ (54 of 63 patients), 100\% (4 of 4), and 72.0\% (18 of 25 ), respectively, for ceftaroline and $69.5 \%$ (41 of 59), $25.0 \%$ ( 1 of 4 ), and $55.6 \%$ (15 of 27) for ceftriaxone, respectively. Clinical cure rates in the mMITTE population for the same pathogens are shown in Table $10 .^{70}$

The effectiveness and safety of treatment with ceftaroline was evaluated retrospectively in 527 patients who were given ceftaroline for 72 hours or more. Sixty-seven percent of patients received treatment for unlicensed indications and $28 \%$ had bacteremia. Eighty percent of the patients had received another antibiotic before initiation of ceftaroline and progressive disease was the basis for switching in $48 \%$. Around $85.8 \%$ of patients were given $600 \mathrm{mg}$ IV ceftaroline 12 hourly and $14.4 \%$ were given an unlicensed dose of $600 \mathrm{mg}$ IV 8 hourly. The median length of therapy with ceftaroline was 6 days. Sixty-two percent of patients had positive cultures and $S$. aureus was the most frequently isolated organism $(83 \%$ [271/327]). Around 88.9\% (241/271) of these patients had MRSA. The study demonstrated a clinical success rate of $88 \%$ (426/484), similar to that observed in previous studies (89.6\%). In S. aureus bloodstream infection (BSI), the clinical (78\%) and microbiological (91\%) success rates were similar to those observed in treatment of $S$. aureus BSI with vancomycin and daptomycin in previous studies. Eight percent (41/527) of the patients had adverse events and 9\% (28/307) readmissions occurred for the same infection within 30 days of discharge. ${ }^{71}$ Favorable outcomes were observed in patients treated with ceftaroline for both licensed and unlicensed indications.

In the clinical trials, ceftaroline proved efficacious, achieved high clinical cure rates, demonstrated high bactericidal activity and was noninferior to vancomycin plus aztreonam in the treatment of cSSTIs, and to ceftriaxone in the treatment of CAP.

\section{Safety and tolerability}

The recommended ceftaroline dose is $600 \mathrm{mg}$ for the treatment of cSSTI and CAP, given intravenously 12 hourly over 60 minutes in patients aged $\geq 18$ years. ${ }^{72}$ The approved length of therapy for cSSTI is 5-14 days and for CAP is 5-7 days. ${ }^{72,73}$ However this is determined by the site and extent of infection and the individual's clinical response.

Ceftaroline dose reduction is recommended when creatinine clearance $(\mathrm{CrCL})$ is $\leq 50 \mathrm{~mL} / \mathrm{min},{ }^{72,73}$ but is not 
necessary in individuals with liver dysfunction. ${ }^{72}$ Safety and efficacy in individuals aged $<18$ years have not yet been confirmed. ${ }^{72,73}$

Information on ceftaroline use in pregnancy is inadequate. In rat and rabbit studies, doses similar to therapeutic levels were not associated with reproductive toxicity. Ceftaroline administration in pregnant rats during organ development was associated with minor changes in fetal weight and delayed parietal bone ossification. ${ }^{72}$ Ceftaroline use in pregnancy is only recommended if the benefit outweighs the risk to the fetus. ${ }^{73}$ Data on ceftaroline excretion in breast milk is lacking, ${ }^{72,73}$ therefore prescribing in lactating women should be done with caution. The effect of ceftaroline on driving and use of machinery has not been studied, however it may cause dizziness. ${ }^{72}$ Ceftaroline should not be used in individuals known to have immediate and severe hypersensitivity to any beta-lactam. Caution should be exercised in those who have any other type of hypersensitivity reaction to penicillins. ${ }^{72}$

Ceftaroline can lead to antimicrobial-associated colitis and pseudomembranous colitis. In the CANVAS 1 trial, two subjects in the ceftaroline-treated group were Clostridium difficile toxin positive. ${ }^{64}$

7-25-fold ceftaroline $C_{\max }$ values are associated with seizures. There is limited experience with ceftaroline in individuals with preexisting fits, therefore caution should be exercised with use in this patient group. ${ }^{72}$ In the FOCUS 2 trial, a convulsion was reported in a 75-year-old male 2 days after stopping ceftaroline; this was deemed mild and likely associated with the study drug. ${ }^{69}$

Interaction of ceftaroline with other drugs has not been studied. It has low potential for interaction with substrates, inhibitors or inducers of CYP450; agents which are secreted by the kidneys; ${ }^{68,72}$ and those that may modify renal blood flow. ${ }^{73}$

Therapy with cephalosporins may lead to seroconversion to a positive direct Coombs' test. ${ }^{68}$ This occurred in 120/1,114 $(10.8 \%)$ of individuals who were given ceftaroline and 49/1,116 (4.4\%) of those who received comparator antibiotics in the four pooled Phase III studies. ${ }^{73}$

In Phase III studies, serious adverse events were reported in $98 / 1,300(7.5 \%)$ of individuals in the ceftaroline group and $100 / 1,297(7.7 \%)$ of those in the comparator groups. Therapy was discontinued in 35/1,300 (2.7\%) of subjects who received ceftaroline and 48/1,297 (3.7\%) of those who were given comparator antibiotics. The most frequent adverse event was hypersensitivity which occurred at a rate of $0.3 \%$ in the ceftaroline group and $0.5 \%$ in the comparator group. Diarrhea, nausea, and rash were the most frequent adverse reactions which occurred in $>2 \%$ of subjects receiving ceftaroline. Constipation, vomiting, increased transaminases, hypokalaemia, and phlebitis were reported in $\geq 2 \%$ of subjects in the ceftaroline group while anemia, raised eosinophils, low neutrophils, low platelets, low heart rate, palpitations, abdominal pain, pyrexia, hepatitis, hypersensitivity, anaphylaxis, $C$. difficile colitis, dizziness, convulsion, renal failure, and urticaria occurred in $<2 \%$ of patients within the same group. ${ }^{73}$

There is lack of experience with ceftaroline therapy in immunosuppressed patients with CAP; patients with severe sepsis or preexisting pulmonary disease; those with severe CAP needing ventilator support; CAP caused by MRSA; patients in need of intensive care; those with necrotizing infections or abscesses; and those with deep and extensive burns. Experience with managing diabetic foot infections is restricted. ${ }^{72}$

\section{Patient-focused perspectives}

Phase III studies have demonstrated high clinical cure rates in patient groups treated with ceftaroline for cSSTIs and CAP, but information on patient satisfaction, acceptability and adherence to therapy with ceftaroline, or patient quality of life following treatment is lacking. Clinical outcomes with ceftaroline therapy need to be evaluated.

Ceftaroline costs US\$41 for a 400 or $600 \mathrm{mg}$ vial. A 7-day course of treatment costs US\$574. ${ }^{26}$ In the UK, the net price of a $600 \mathrm{mg}$ vial is $£ 37.50$. $^{74}$

\section{Discussion}

Ceftaroline has excellent bactericidal activity against common causes of cSSTIs and CAP..$^{26,54,56-58}$ It demonstrated noninferiority and high clinical cure rates when compared with vancomycin plus aztreonam in the treatment of cSSTIs, ${ }^{64-66}$ and also when compared with ceftriaxone in the treatment of CAP. ${ }^{68-70}$ Its clinical response was numerically higher than vancomycin plus aztreonam on day 3 of treatment in a retrospective analysis of patients enrolled in the CANVAS trial. ${ }^{67}$ A retrospective evaluation of its effectiveness and safety demonstrated favorable outcomes with ceftaroline therapy for both regulatory-approved and unlicensed indications. ${ }^{71}$

Ceftaroline has a similar safety profile to that of other cephalosporins and studies have reported the most frequent adverse reactions as mild. It has low potential to interact with other drugs. ${ }^{73}$

It is inactive against ESBL-producing or AmpCoverexpressing Enterobacteriaceae and is minimally active against non-fermenting gram-negative bacilli. ${ }^{54}$ 
Similar to use of other antibiotics (including cephalosporins), C. difficile-associated diarrhea occurred during treatment with ceftaroline. ${ }^{64}$

Ceftaroline in contraindicated in individuals with severe hypersensitivity to beta-lactams and there is limited data on its use in pediatric, pregnant, and breast-feeding patients. ${ }^{73}$ There is also lack of experience with ceftaroline treatment in patients with compromised immunity, severe sepsis, CAP requiring intensive care and ventilation, MRSA CAP, and necrotizing fasciitis. ${ }^{72}$ Since it can only be administered parenterally 12 hourly, ceftaroline is not ideal for outpatient parenteral antibiotic therapy.

\section{Conclusion}

Ceftaroline is a safe and effective antibiotic that can be used in the treatment of cSSTIs and CAP, including infections due to MRSA, Staphylococcus aureus strains with reduced susceptibility to vancomycin and linezolid, and multidrug resistant Streptococcus pneumoniae. Its broad-spectrum coverage, bactericidal activity, and excellent safety profile support its use as an alternative treatment of cSSTIs and CAP. However, further studies are needed to determine its safety and efficacy in off-label infections. The clinical outcomes observed in clinical trials also need to be evaluated in order to determine patient-focused perspectives such as quality of life.

\section{Disclosure}

Professor Alasdair P MacGowan has received Speaker Fees and Departmental Research Grants from AstraZeneca. The authors report no other conflicts of interest in this work.

\section{References}

1. Stevens DL, Bisno AL, Chambers HF, et al. IDSA guidelines: practice guidelines for the diagnosis and management of skin and soft-tissue infections. Clin Infect Dis. 2005:41(10):1373-1406.

2. Dryden MS. Complicated skin and soft tissue infections. J Antimicrob Chemother. 2010;65(Suppl 3):iii35-iii44.

3. Eron LJ, Lipsky BA, Low DE, et al. Managing skin and soft tissue infections:expert panel recommendations on key decision points. $J$ Antimicrob Chemother. 2003;52(Suppl 1):i3-i17.

4. Diekema DJ, Pfaller MA, Schmitz FJ, et al. Survey of infections due to Staphylococcus species: frequency of occurrence and antimicrobial susceptibility of isolates collected in the United States, Canada, Latin America, Europe, and the Western Pacific region for the SENTRY Antimicrobial Surveillance Program,1997-1999. Clin Infect Dis. 2001;32:S114-S132.

5. Di Nubile MJ, Lipsky BA. Complicated infections of the skin and skin structures: when the infection is more than skin deep. $J$ Antimicrob Chemother. 2004;53(Suppl 2):ii37-ii50.

6. Jevons MP. Celbenin-resistant staphylococci. Br Med J. 1961;1:124-125.

7. Wenzel RP, Nettleman MD, Jones RN, et al. Methicillin-resistant Staphylococcus aureus: implications for the 1990s and effective control measures. Am J Med. 1991;91:221S-227S.
8. Grundmann H, Aires-de-Sousa M, Boyce J, et al. Emergence and resurgence of methicillin-resistant Staphylococcus aureus as a public health threat. Lancet. 2006;368:874-885.

9. Moet GJ, Jones RN, Biedenbach DJ, et al. Contemporary causes of skin and soft tissue infections in North America, Latin America, and Europe: report from the SENTRY Antimicrobial Surveillance Program (1998-2004). Diagn Microbiol Infect Dis. 2007;57:7-13.

10. Bruce AM, Spencer JM. Prevalence of community-acquired methicillinresistant Staphylococcus aureus in a private dermatology office. J Drugs Dermatol. 2008;7:751-755.

11. Dryden MS. Complicated skin and soft tissue infections caused by MRSA: epidemiology, risk factors and presentation. Surg Infect. 2008; 9(Suppl 1):S3-S10.

12. Chen CJ, Huang YC. New epidemiology of Staphylococcus aureus infection in Asia. Clin Microbiol Infect. 2014;20(7):605-623.

13. Young DM, Harris HW, Charlebois ED, et al. An epidemic of MRSA soft tissue infections among medically underserved patients. Arch Surg. 2004;139:947-951.

14. Moran GJ, Krishnadasan A, Gorwitz RJ, et al. Methicillin-resistant S. aureus infections among patients in the emergency department. $N \mathrm{Engl}$ $J$ Med. 2006;355:666-674.

15. Ray GT, Suaya JA, Baxter R. Incidence, microbiology and patient characteristics of skin and soft-tissue infections in a U.S. population: a retrospective population-based study. BMC Infect Dis. 2013; $13: 252$.

16. Antimicrobial Resistance Surveillance in Europe 2012. Available from: http://www.ecdc.europa.eu/en/publications/Publications/antimicrobialresistance-surveillance-europe-2012.pdf. Accessed January 9, 2015.

17. Dryden M, Andrasevic AT, Bassetti M, et al. A European survey of antibiotic management of methicillin-resistant Staphylococcus aureus infection: current clinical opinion and practice. Clin Microbiol Infect. 2010;16(Suppl 1):3-30.

18. Sader HS, Farrell DJ, Jones RN. Antimicrobial susceptibility of gram-positive cocci isolated from skin and skin-structure infections in European medical centres. Int J Antimicrob Agents. 2010;36:28-32.

19. Johnson AP. Methicillin-resistant Staphylococcus aureus: the European landscape. J Antimicrob Chemother. 2011;66(Suppl 4): iv43-iv48.

20. Health Protection Agency. Surveillance of Healthcare Associated Infections Report 2008. Available from: http://www.hpa.org.uk/webc/ HPAwebFile/HPAweb_C/1216193833496. Accessed April 29, 2014.

21. Health Protection Agency. Healthcare-associated infections and antimicrobial resistance: 2009/10. Available from: http://webarchive. nationalarchives.gov.uk/20140714084352/http://www.hpa.org.uk/webc/ HPAwebFile/HPAweb_C/1281954479045. Accessed April 29, 2014.

22. Li JS, Sexton DJ, Mick N, et al. Proposed modifications to the Duke criteria for the diagnosis of infective endocarditis. Clin Infect Dis. 2000;30: 633-638.

23. White B, Seaton RA. Complicated skin and soft tissue infections: literature review of evidence for and experience with daptomycin. Infect Drug Resist. 2011;4:115-127.

24. Eisenstein BI. Treatment challenges in the management of complicated skin and soft-tissue infections. Clin Microbiol Infect. 2008;14(Suppl 2): $17-25$.

25. Gemmel CG, Edwards DI, Fraise AP, et al. Guidelines for the prophylaxis and treatment of methicillin-resistant Staphylococcus aureus (MRSA) infections in the UK. J Antimicrob Chemother. 2006; 57(4):589-608.

26. Hernandez PO, Lema S, Tyring SK, Mendoza N. Ceftaroline in complicated skin and skin-structure infections. Infect Drug Resist. 2012;5: 23-35.

27. Boucher H, Miller LG, Razonable RR. Serious infections caused by methicillin-resistant Staphylococcus aureus. Clin Infect Dis. 2010; 51(Suppl 2):S183-S197.

28. Mandell GL, Bennett JE, Dolin R. Mandell, Douglas, and Bennett's Principles and Practice of Infectious Diseases. 7th ed. Philadelphia, PA: Churchill Livingstone Elsevier; 2009. 
29. Torok E, Moran E, Cooke F. Oxford Handbook of Infectious Diseases and Microbiology. Oxford, UK: Oxford University Press; 2009.

30. Manuel RJ, Tuck A, Lowes A, Pallet A. Southampton Public Health Laboratory. Detection of teicoplanin resistance in UK EMRSA-17 strains. J Antimicrob Chemother. 2002;50(6):1089-1090.

31. Watkins RR, Lemonovich TL. Diagnosis and management of community-acquired pneumonia in adults. Am Fam Physician. 2011; 83(11):1299-1306.

32. Centers for Disease Control and Prevention. FastStats pneumonia: deaths and mortality. Available from: http://www.cdc.gov/nchs/fastats/ pneumonia.htm. Accessed April 29, 2014.

33. Lim WS, Baudouin SV, George RC, et al. Pneumonia guidelines committee of the BTS standards of care committee. BTS guidelines for the management of community acquired pneumonia in adults: update 2009 . Thorax. 2009;64(Suppl 3):1-55.

34. File TM Jr, Marrie TJ. Burden of community-acquired pneumonia in North American adults. Postgrad Med. 2010;122(2):130-141.

35. Millett ERC, Quint JK, Smeeth L, Daniel RM, Thomas SL. Incidence of community-acquired lower respiratory tract infections and pneumonia among older adults in the United Kingdom: a population-based study. PLoS One. 2013;8(9):e75131.

36. Jokinen C, Heiskanen L, Juvonen H, et al. Incidence of communityacquired pneumonia in the population of four municipalities in eastern Finland. Am J Epidemiol. 1993;137:977-188.

37. Froes F. Community-acquired pneumonia in adults in mainland Portugal - incidence and mortality in hospital inpatients between 1998 and 2000. Rev Port Pneumol. 2003:187-194. Portugese.

38. Trotter CL, Stuart JM, George R, et al. Increasing hospital admissions for pneumonia, England. Emerg Infect Dis. 2008;14:727e33.

39. Niederman MS. Challenges in the management of community-acquired pneumonia: the role of quinolones and moxifloxacin. Clin Infect Dis. 2005;41(Supp1 2):S158-S166.

40. Niederman MS, Mandell LA, Anzueto A, et al. Guidelines for the management of adults with community-acquired pneumonia: diagnosis, assessment of severity, antimicrobial therapy, and prevention. Am J Respir Crit Care Med. 2001;163:1730-1754.

41. Mongkolrattanothai K, Boyle S, Kahana MD, Daum RS. Severe Staphylococcus aureus infections caused by clonally related community acquired methicillin-susceptible and methicillin-resistant isolates. Clin Infect Dis. 2003;37:1050-1058.

42. File TM Jr. Current challenges in the treatment of community-acquired pneumonia. Clin Infect Dis. 2004;38(Suppl 1):S1-S4.

43. Breiman RF, Butler JC, Tenover FC, Elliott JA, Facklam RR. Emergence of drug-resistant pneumococcal infections in the United States. JAMA. 1994;271:1831-1835.

44. Karlowsky JA, Thornsberry C, Jones ME, Evangelista AT, Critchley IA, SahmDF. Factors associated with relative rates of antimicrobial resistance among Streptococcus pneumoniae in the United States: results from the TRUST Surveillance Program (1998-2002). Clin Infect Dis. 2003;36:963-970.

45. Thornsberry C, Sahm DF, Kelly LJ, et al. Regional trends in antimicrobial resistance among clinical isolates of Streptococcus pneumoniae, Haemophilus influenzae, and Moraxella catarrhalis in the United States: results from the TRUST Surveillance Program, 1999-2000. Clin Infect Dis. 2002;34(Suppl 1):S4-S16.

46. Jenkins SG, Brown SD, Farrell DJ. Trends in antibacterial resistance among Streptococcus pneumoniae isolated in the USA: update from PROTEKT US Years 1-4. Ann Clin Microbiol Antimicrob. 2008;7:1.b.

47. Sahm DF, Brown NP, Thornsberry C, Jones ME. Antimicrobial susceptibility profiles among common respiratory tract pathogens: a GLOBAL perspective. Postgrad Med. 2008;120(3 Suppl 1):16-24.

48. Hoa NQ, Trung NV, Larsson M, et al. Decreased Streptococcus pneumoniae susceptibility to oral antibiotics among children in rural Vietnam: a community study. BMC Infect Dis. 2010;10:85.
49. Kosowski-Shick K, McGhee P, Appelbaum P. Affinity of ceftraoline and other beta-lactams for penicillin-binding proteins from Staphylococcus aureus and Strepotococcus pneumoniae. Antimicrob Agents Chemother. 2010;54:1670-1677.

50. Mushtaq S, Warner M, Ge Y, Kaniga K, Livermore D. In vitro activity of ceftaroline (PPI-0903M, T-91825) against bacteria with defined resistance mechanisms and phenotypes. J Antimicrob Chemother. 2007; 60:300-311

51. Ishikawa $\mathrm{T}$, Matsunaga $\mathrm{N}$, Tawada $\mathrm{H}$, et al. TAK-599, a novel N-phosphono type prodrug of anti-MRSA cephalosporin T-91825: synthesis, physicochemical and pharmacological properties. Bioorg Med Chem. 2003;11:2427-2437.

52. Moisan H, Pruneau M, Malouin F. Binding of ceftaroline to penicillinbinding proteins of Staphylococcus aureus and Streptococcus pneumoniae. J Antimicrob Chemother 2010;65:713-716.

53. Villegas-Estrada A, Lee M, Hesek D, et al. Co-opting the cell wall in fighting methicillin-resistant Staphylococcus aureus: potent inhibition of PBP 2a by two anti-MRSA b-lactam antibiotics. $J$ Am Chem Soc. 2008;130:9212-9213.

54. Biek D, Critchley IA, Riccobene TA, Thye DA. Ceftaroline fosamil: a novel broad-spectrum cephalosporin with expanded anti-gram-positive activity. J Antimicrob Chemother. 2010;65(Suppl 4):iv9-iv16.

55. Saravolatz LD, Stein GE, Johnson LB. Ceftaroline: a novel cephalosporin with activity against methicillin-resistant Staphylococcus aureus. Reviews of anti-infective agents. Clin Infect Dis. 2011;52: 1156-1163.

56. Ge Y, Biek D, Talbot GH, Sahm DF. In vitro profiling of ceftaroline against a collection of recent bacterial clinical isolates from across the United States. Antimicrob Agents Chemother. 2008;52(9):3398-3407.

57. McGee L, Biek D, Ge Y, et al. In vitro evaluation of the antimicrobial activity of ceftaroline against cephalosporin-resistant isolates of Streptococcus pneumonia. Antimicrob. Agents Chemother. 2009;53(2):552.

58. Doern GV, Diekema DJ, Heilmann KP, Dohrn CL, Riahi F, Richter SS. In vitro activity of ceftaroline against clinical isolates of Streptococcus pneumoniae recovered in 43 U.S. medical centers during 2010-2011. Antimicrob. Agents Chemother. 2012;56(6):3406.

59. Riccobene T, Fang E, Thye DA. A single-and multiple-dose study to determine the safety, tolerability, and pharmacokinetics (PK) of ceftaroline (CPT) administered by intramuscular (IM) injection to healthy subjects [Abstract 1888]. In: Program and abstracts of the 48th Interscience Conference on Antimicrobial Agents and Chemotherapy-46th Annual Meeting of the Infectious Diseases Society of America. Washington, DC: American Society of Microbiology; 2008.

60. Ge JY, Hubbel A. In vitro evaluation of plasma protein binding and metabolic stability of ceftaroline (PPI-0903M) [Abstract 1935]. In: Program and abstracts of the 46th Interscience Conference on Antimicrobial Agents and Chemotherapy. San Francisco, CA; 2006.

61. Mouton JW, Dudley MN, Cars O, et al. Standardization of pharmacokinetic/pharmacodynamic (PK/PD) terminology for anti-infective drugs: an update. J Antimicrob Chemother. 2005;55:601-607.

62. MacGowan AP, Noel AR, Tomaselli S, Bowker KE. Pharmacodynamics of ceftaroline against Staphylococcus aureus studied in an in vitro pharmacokinetic model of infection. Antimicrob Agents Chemother. 2013;57(6):2451

63. Talbot GH, Thye D, Das A, Ge Y. Phase 2 study of ceftaroline versus standard therapy in treatment of complicated skin and skin structure infections. Antimicrob Agents Chemother. 2007;51(10):3612.

64. Corey GR, Wilcox MH, Talbot GH, Thye D, Friedland D, Baculik T. CANVAS 1: the first Phase III, randomized, double-blind study evaluating ceftaroline fosamil for the treatment of patients with complicated skin and skin structure infections. J Antimicrob Chemother. 2010;65(Suppl 4): iv41-iv51.

65. Wilcox MH, Corey GR, Talbot GH, et al. CANVAS 2: the second Phase III, randomized, double-blind study evaluating ceftaroline fosamil for the treatment of patients with complicated skin and skin structure infections. J Antimicrob Chemother. 2010;65(Suppl 4):iv53-iv65. 
66. Corey GR, Wilcox M, Talbot GH, et al. Integrated analysis of CANVAS 1 and 2: Phase 3, multicenter, randomized, double-blind studies to evaluate the safety and efficacy of ceftaroline versus vancomycin plus aztreonam in complicated skin and skin-structure infection. Clin Infect Dis. 2010;51(6):641-650.

67. Friedland HD, O'Neal T, Biek D, et al. CANVAS 1 and 2: Analysis of clinical response at day 3 in two phase 3 trials of ceftaroline fosamil versus vancomycin plus aztreonam in treatment of acute bacterial skin and skin structure infections. Antimicrob Agents Chemother. 2012;56(5):2231.

68. File JM Jr, Low DE, Eckburg PB, et al. FOCUS 1: a randomized, double-blinded, multicentre, Phase III trial of the efficacy and safety of ceftaroline fosamil versus ceftriaxone in community-acquired pneumonia. J Antimicrob Chemother. 2011;66(Suppl 3):iii19-iii32.

69. Low DE, File TM Jr, Eckburg PB, et al. FOCUS 2: a randomized, double-blinded, multicentre, Phase III trial of the efficacy and safety of ceftaroline fosamil versus ceftriaxone in community-acquired pneumonia. J Antimicrob Chemother. 2011;66(Suppl 3):iii33-iii44.
70. File TM Jr, Low DE, Eckburg PB, et al. Integrated analysis of FOCUS 1 and FOCUS 2: randomized, doubled-blinded, multicenter phase 3 trials of the efficacy and safety of ceftaroline fosamil versus ceftriaxone in patients with community-acquired pneumonia. Clin Infect Dis. 2010;51(12):1395-1405.

71. Casapao AM, Davis SL, Barr VO, et al. Large retrospective evaluation of the effectiveness and safety of ceftaroline fosamil therapy. Antimicrob Agents Chemother.2014;58(5):2541.

72. medicines.org.uk. Zinforo. Available from: http://www.medicines.org. uk/emc/medicine/26988/SPC/Zinforo+600+mg+powder+for+concent rate+for+solution+for+infusion/. Accessed Januray 9, 2015.

73. Teflaro [prescribing information]. Teramo, Italy: Forest Laboratories, Inc; 2010-2012.

74. British National Formulary. 66th Edition, September 2013 - March 2014. BMJ Group and Royal Pharmaceutical Society of Great Britain 2013:363.
Therapeutics and Clinical Risk Management

\section{Publish your work in this journal}

Therapeutics and Clinical Risk Management is an international, peerreviewed journal of clinical therapeutics and risk management, focusing on concise rapid reporting of clinical studies in all therapeutic areas outcomes, safety, and programs for the effective, safe, and sustained use of medicines. This journal is indexed on PubMed Central, CAS,

\section{Dovepress}

EMBase, Scopus and the Elsevier Bibliographic databases. The manuscript management system is completely online and includes a very quick and fair peer-review system, which is all easy to use. Visit http://www.dovepress.com/testimonials.php to read real quotes from published authors.

Submit your manuscript here: http://www.dovepress.com/therapeutics-and-clinical-risk-management-journal 